\title{
A new method for determination of most likely landslide initiation points and the evaluation of digital terrain model scale in terrain stability mapping
}

\author{
P. Tarolli ${ }^{1}$ and D. G. Tarboton ${ }^{2}$ \\ ${ }^{1}$ Department of Land and Agroforest Environments, AGRIPOLIS, University of Padova, 35020 Legnaro, Padova, Italy \\ ${ }^{2}$ Department of Civil and Environmental Engineering, Utah State University, Logan, Utah, USA
}

Received: 10 January 2006 - Published in Hydrol. Earth Syst. Sci. Discuss.: 6 April 2006

Revised: 5 July 2006 - Accepted: 21 September 2006 - Published: 27 September 2006

\begin{abstract}
This paper introduces a new approach for determining the most likely initiation points for landslides from potential instability mapped using a terrain stability model. This approach identifies the location with critical stability index from a terrain stability model on each downslope path from ridge to valley. Any measure of terrain stability may be used with this approach, which here is illustrated using results from SINMAP, and from simply taking slope as an index of potential instability. The relative density of most likely landslide initiation points within and outside mapped landslide scars provides a way to evaluate the effectiveness of a terrain stability measure, even when mapped landslide scars include run out zones, rather than just initiation locations. This relative density was used to evaluate the utility of high resolution terrain data derived from airborne laser altimetry (LIDAR) for a small basin located in the Northeastern Region of Italy. Digital Terrain Models were derived from the LIDAR data for a range of grid cell sizes (from 2 to $50 \mathrm{~m}$ ). We found appreciable differences between the density of most likely landslide initiation points within and outside mapped landslides with ratios as large as three or more with the highest ratios for a digital terrain model grid cell size of $10 \mathrm{~m}$. This leads to two conclusions: (1) The relative density from a most likely landslide initiation point approach is useful for quantifying the effectiveness of a terrain stability map when mapped landslides do not or can not differentiate between initiation, runout, and depositional areas; and (2) in this study area, where landslides occurred in complexes that were sometimes more than $100 \mathrm{~m}$ wide, a digital terrain model scale of $10 \mathrm{~m}$ is optimal. Digital terrain model scales larger than $10 \mathrm{~m}$ result in loss of resolution that degrades the results, while for digital terrain model scales smaller than 10
\end{abstract}

Correspondence to: P. Tarolli

(paolo.tarolli@unipd.it) $\mathrm{m}$ the physical processes responsible for triggering landslides are obscured by smaller scale terrain variability.

\section{Introduction}

Landsliding associated with rainstorms is a major process of landscape evolution on steep hillslopes. Shallow landsliding in steep, soil-mantled landscapes can generate debris flows which scour low-order channels, deposit large quantities of sediment in higher order channels and pose a significant hazard. The hazard occurs where development has encroached on debris flow source and run-out areas. A variety of approaches are available to assess landslide hazard and produce maps portraying its spatial distribution (landslide hazard mapping). In the last decade, process-based theories and models have been developed that represent the essential processes controlling shallow landsliding, yet remain simple enough that they can be calibrated and validated using observed landslides inventories. Many of these Terrain Stability Models are based upon the infinite slope stability model (e.g. Hammond et al., 1992; Montgomery and Dietrich, 1994; Wu and Sidle, 1995). Dietrich et al. (1992) and Montgomery and Dietrich (1994) developed a simple physically based model, SHALSTAB, based on digital terrain data, which couples a shallow steady state saturated subsurface flow model with an infinite slope stability model. SHALSTAB is based on the assumptions that shallow subsurface flow dictates the pore pressure field and that steady state flow mimics the spatial pattern of soil pore pressures during transient storms and can be used to map the relative potential for shallow landsliding across a landscape. Pack et al. (1998) introduced a stability index approach (SINMAP) to terrain stability mapping, a methodology based upon the same concepts as Montgomery

Published by Copernicus GmbH on behalf of the European Geosciences Union. 
and Dietrich (1994) in that it combines steady-state hydrologic concepts with the infinite slope stability model. SINMAP differs however in that parameter uncertainty is incorporated through the use of uniform probability distributions for uncertain parameters and that rather than critical rainfall, the measure of stability used is the probability that factor of safety is greater than 1 .

The steady state subsurface flow assumptions used by Montgomery and Dietrich (1994) and incorporated into SINMAP (Pack et al., 1998) have been criticized for being restrictive (Iverson, 2000). Iverson's analysis, based on Richards equation for unsaturated subsurface flow, suggested that the time scale necessary for establishment of steady state conditions was significantly larger than most rainstorms. Consequently, he questioned the use of models based on steady state assumptions. Hillslope flow processes that lead to the build up of pore pressures that trigger landslides are complex and sometimes involve preferential pathways not always amenable to description using the Richards equation that was the basis for Iverson's criticism. Nevertheless, following Beven et al. (1995) we feel that the general tendency of water to flow downhill is amenable to macroscale conceptualization and that the approach of SINMAP (Pack et al., 1998) and SHALSTAB (Montgomery and Dietrich, 1994) that relate the relative wetness at a location to the upslope contributing area captures these topographic effects in a simple way. Basically these models represent relative wetness as $R a$, where $a$ is the specific catchment area (contributing area per unit contour width) and $R$ is a constant that can be interpreted as steady state infiltration. But $R$ can also more generally be interpreted as a proportionality constant reflecting the likelihood of greater wetness and higher pore pressures in convergent areas with larger $a$. Barling et al. (1994) developed a quasi-dynamic wetness index that addresses some of the shortcomings of a steady state wetness index, but requires more detailed information on storm duration and soil properties. Borga et al. (2002) use a quasi-dynamic wetness index in response to a rainfall of a specific duration and frequency to develop a more general terrain stability model. Wu and Sidle (1995) simulate pore pressure build up in response to a specific time series of rainfall inputs using an explicit spatially distributed model. While these more detailed approaches clearly represent significant advances, they demand more information about landslide triggering rainstorms than is typically available when the purpose is identification of potential instability for screening or planning purposes. They also require more detailed information on soil properties.

Methods to spatially evaluate slope stability models lag the development of models themselves. Dietrich et al. (2001) evaluated the SHALSTAB model using landslide density and cumulative percent of landslides and area in each stability index class. Borga et al. (2002) extended the cumulative percent idea to cumulative frequency plots of stability index at mapped landslide initiation locations in comparison to the cumulative frequency over the entire domain to quantify the discriminating capability of a terrain stability map. Chinnayakanahalli (2004) used a similar approach but extended this to construct a threshold independent integral comparison measure from the integral of cumulative frequency plots that could be used with a generalized likelihood uncertainty estimation approach to optimize model parameters and quantify uncertainty. Increasingly statistical methods involving split sampling techniques, either in time or space are also being used with measures of a terrain stability model's discriminating capability to evaluate terrain stability models (e.g. Chung and Fabbri, 2003, 2005; Brenning, 2005). Begueria (2006) discusses the difficulties associated with validating natural hazard models due to the different proportion of positive and negative cases in typical data. He uses a threshold independent receiver operating characteristic plot and its integral as a global accuracy statistic.

The accuracy of procedures relying on process-based theories depends on the quality of topographic data and is limited by the underlying assumptions used in the models, which cannot account for many factors which are known to influence landslide hazard, such as mechanically weak rocks, springs, locally high or low root strength and soil thickness, to name a few. With respect to the quality, and resolution of topographic data the accuracy of base point survey data and the method used to interpolate the Digital Terrain Model from point survey data can influence the results of terrain stability models. New survey techniques have been introduced in the last few years; an example of these is the use of laser sensors on aircraft (Akermann, 1999; Kraus and Pfeifer, 2001; Briese, 2004). This technology, named LIDAR (LIght Detection And Ranging), provides high quality digital terrain data, and provides more information about land cover than was previously available. The application of airborne laser altimetry technology to slope stability modeling has the potential to improve model performance and benefit land management.

There may be some limitations to the improvement of landslide modeling which can be achieved by using very fine resolution topographic data. Regardless of the algorithms or type of digital terrain model used, all digital terrain model analyses depend crucially on the assumption that the flow pathways will be predominantly controlled by the surface topography of the catchment. Even in shallow systems, the bedrock topography may have a greater control on downslope saturated flow than the surface topography (Freer et al., 2002). It is likely that differences between surface and bedrock topography is relatively greater at very fine digital terrain model resolution; therefore, very fine topographic data may lose representativeness for the modeling of subsurface flow. At very fine resolution slopes from the DTM may also lose their representativeness as the slope of the failure surface in the infinite slope stability model. There are thus physical and modeling limits on the utility of fine resolution terrain data. 
Practical limits on LIDAR accuracy are still being defined (McKean and Roering, 2004). Data errors can be described as those originating from the hardware/software components of the LIDAR system, those related to the mission design and conduct, and those associated with the laser target characteristics (e.g. topography and vegetation contamination in the distribution of lidar elevation data points) (McKean and Roering, 2004).

In this paper we present a new method for determining the most likely landslide initiation points. This method is referred to as MLIP. The method introduced identifies the grid cell with critical (lowest) stability index on each downslope path from ridge to valley. If a stability index threshold is specified the MLIP are a subset of the points with stability index less than the threshold with the special property that they are flow path specific minima. This makes MLIP points better points to use in the evaluation of a terrain stability model when the observations being used to evaluate the model are not limited to initiation locations, but include run out and deposition areas. A stability index attempts to quantify the potential for landslide initiation. Evaluation of the effectiveness of a stability index is inhibited when observations do not separate initiation from run out and deposition areas. The use of MLIP avoids these problems and tabulation of the density of MLIP points inside and outside such mapped areas provides a quantification of the effectiveness of a terrain stability model in terms of the density of points within the mapped landslide scar where landslides are most likely to have initiated. The use of a threshold avoids identification of stable locations as MLIP on flow paths that do not contain any unstable locations. We evaluate the benefits of this method and the sensitivity to varying the grid size resolution of the digital terrain model used for mapping landslide areas with this method. The most likely landslide initiation point approach can be applied with any spatial index of terrain stability, empirically or physically derived. Here the most likely landslide initiation approach was applied using terrain slope as a simple empirical measure of terrain stability. The most likely landslide initiation point approach was then also applied to a Stability Index field obtained from SINMAP using the default parameters suggested by Pack et al. (1998). The SINMAP stability index is used as a convenient example for the development and evaluation of this method. Comparisons of the most likely landslide initiation point approach applied to SINMAP SI and to slope demonstrates how the most likely landslide initiation points can be used to compare two different terrain stability models.

The flow paths used to evaluate most likely landslide initiation locations were determined from the $D \infty$ algorithm introduced by Tarboton (1997) and available as part of the open source TauDEM software (http://www.engineering.usu.edu/ dtarb/taudem). A range of stability index threshold values were used to define most likely landslide initiation points. The ratio of the density of most likely landslide initiation points inside and outside mapped landslide areas was used to quantify the ability of the terrain stability map to discriminate terrain instability. High values of the most likely landslide initiation point density ratio indicate good model performance. This approach was applied to a study area located in Northern Region of Italy where landslide runout areas had been mapped from high resolution aerial photographs. The broad question that we address is: What is the influence of high resolution LIDAR derived digital terrain model on terrain stability mapping? Specifically we examined what additional information is obtained from the most likely landslide initiation point method with respect to the standard approach for mapping landslides based on a stability index, and how sensitive is the most likely landslide initiation point method to the digital terrain model grid resolution?

The paper is divided into six sections. In Sect. 2 we define most likely landslide initiation points. Section 3 describes the field area in Northern Italy where the approach was tested. Section 4 describes the method used to calculate the density of most likely landslide initiation points within mapped landslide runout zones used to evaluate the model. Sections 5 and 6 present and discuss the results. In Sect. 7 we conclude with a summary of our findings.

\section{Most likely landslide initiation point definition}

A most likely landslide initiation point (MLIP) is defined as the point along each flow path that has critical value of a stability index corresponding to the most unstable location along the flow path. This is illustrated in Fig. 1 using a terrain stability index map obtained from SINMAP. Figure 1a shows four flow paths from ridge top to valley and along each path the grid cell with lowest SINMAP stability index is identified. In Fig. 1b the most likely landslide initiation points along all flow lines are identified. Physically, most likely landslide initiation points are the most unstable points along a downslope path from ridge to valley according to the terrain stability model being used. Conceptually they can be identified by tracing down from each grid cell until one exits the region and marking the point where stability index is critical. Depending on the stability index being used, the most critical stability index may be the lowest index value, as in the case of SINMAP, or the highest index value, as in the case of slope. The actual algorithm for identifying most likely landslide initiation points works somewhat differently to take advantage of the efficiency of recursive geographic information system calculations.

\section{Study area}

\subsection{Setting}

The study area is the Miozza catchment, located in Carnia, a tectonically active alpine region of north-eastern Italy 


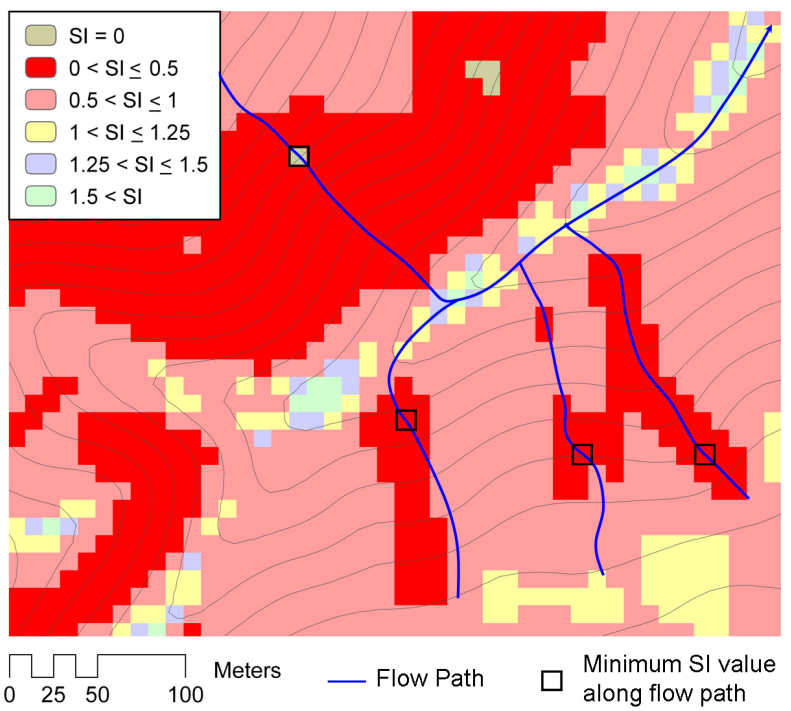

(b)

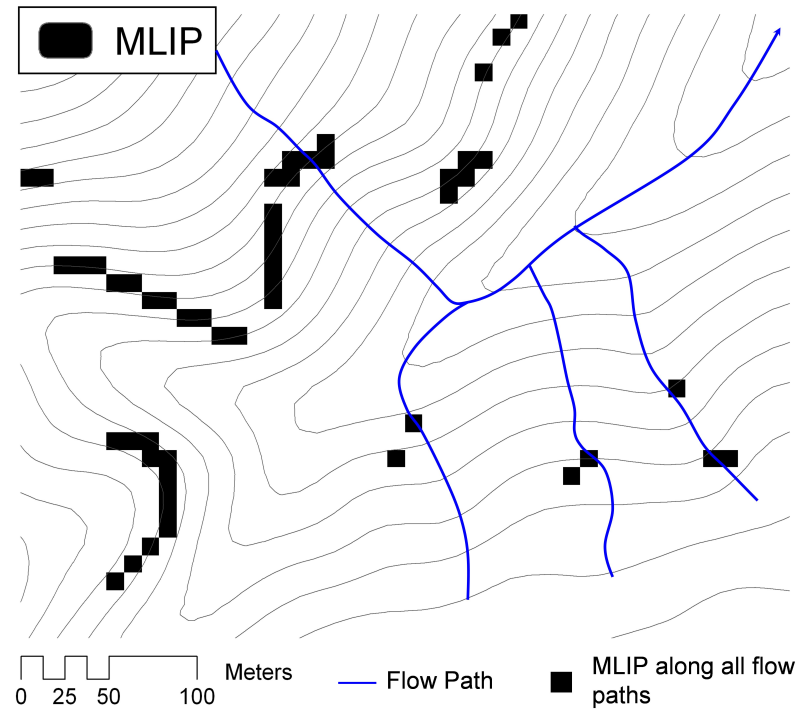

Fig. 1. Illustration of most likely landslide initiation points (MLIP). (a) SINMAP Stability Index (SI) map with the locations of the lowest stability index value along four example flow paths identified. (b) most likely landslide initiation points identified for all flow paths.

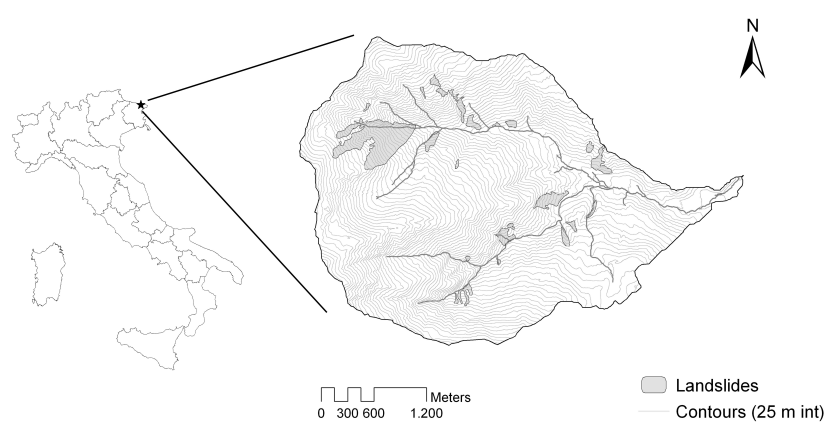

Fig. 2. Miozza basin location map.

(Fig. 2). The area of the Miozza basin is $10.7 \mathrm{~km}^{2}$. Elevation ranges from 471 to $2075 \mathrm{~m}$ a.s.l. with an average value of $1244 \mathrm{~m}$ a.s.l. The slope angle has an average value of $33^{\circ}$ with a maximum value of $77^{\circ}$. The only significant human activity in the basin is forestry. The area has a typical North Eastern Alpine climate with short dry periods and a mean annual precipitation of about $2200 \mathrm{~mm}$. Recorded annual precipitation ranges from 1300 to $2500 \mathrm{~mm}$. Precipitation occurs mainly as snowfall from November to April; runoff is usually dominated by snowmelt in May and June. During summer, flash floods with heavy solid transport are common. Vegetation covers $94 \%$ of the area and consists of forest stands (74\%), shrubs (10\%) and mountain grassland $(10 \%)$; the remaining $6 \%$ of the area is unvegetated landslide scars and deposits. The geomorphologic setting of the basin is typical of the eastern alpine region, with deeply incised valleys. Soil thickness varies between $0.2 \mathrm{~m}$ and $0.5 \mathrm{~m}$ on topographic spurs to depths of up $1.5 \mathrm{~m}$ in topographic hollows. Part of the soil of Miozza basin is characterized by morain formations with vegetated talus deposits. These cover the $40 \%$ of total area. Other soils are calcareous, calcareous-marly, and arenaceous formations that cover the $35 \%$ of total area. The Miozza basin was chosen as a study area because it is representative of the lithological and physiographical conditions frequently observed in the Carnia region where mapping landslide impacts is of interest, and because detailed topographic, land use and geomorphologic information from various sources (including LIDAR) is available. Meteorological data are also available from the regional weather service. Within the study area landslides have been mapped and the area of erosion and shallow landslide scars amounts to $0.5 \mathrm{~km}^{2}$, i.e. about $4.7 \%$ of the total catchment area. The average slope of the landslide scar area is $39^{\circ}$. Most of these areas, in particular the largest single landslide area $\left(0.22 \mathrm{~km}^{2}\right)$, are located at the head of the basin and occur in complexes (Fig. 3) that result from the aggregation of many shallow landslides. Some of the landslides occurred at the bedrock interface while others occurred in the upper part of soil ( $\sim 0.5 \mathrm{~m}$ deep). We do not have data on the specific rainfall that triggered the landslides. The occurrence of landslides in complexes is not the result of a specific rainstorm event, but a combined effect of different events including both extreme short rainfalls, low intensity long duration rainfalls, and snow melt. All the landslides mapped in this study are believed to be shallow translational landslides.

\subsection{Data}

Aerial photography, at a resolution of $0.5 \mathrm{~m}$, and field mapping was used to develop a detailed inventory of sediment 


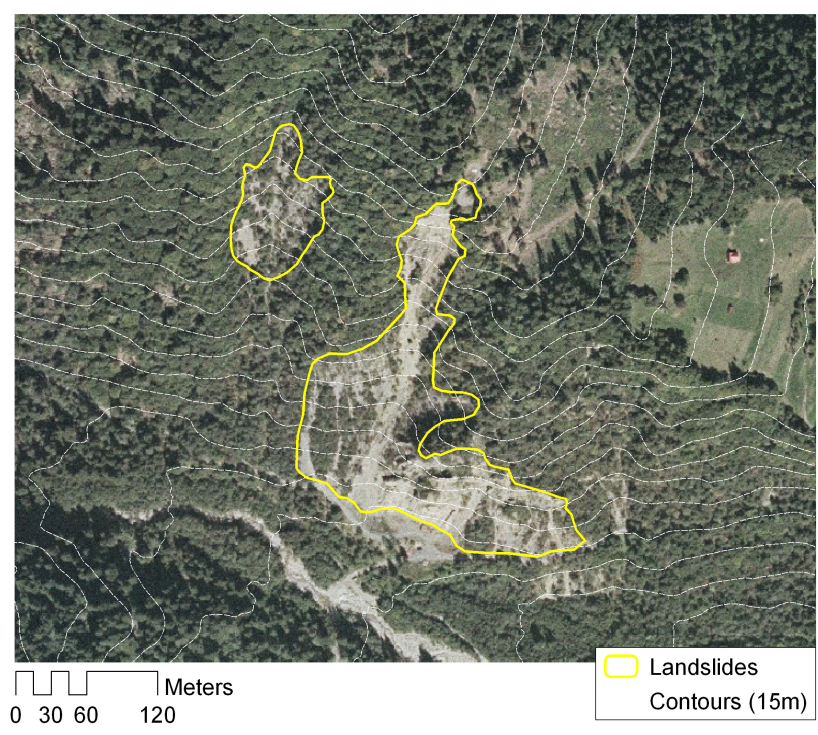

Fig. 3. Miozza basin landslide scars identified from aerial photography: illustration of a landslide complex.

source, erosion and landslide scars within the study area as illustrated in Figs. 2 and 3. The mapped landslides comprised the entire landslide scar, including runout zone, not limited to the locations where the landslides initiated. The most recent aerial photographs obtained in Autumn 2004 were used to identify recent landslides not present in earlier surveys. The landslides identified in the aerial photographs were checked in the field.

LIDAR data was collected during snow free conditions in November 2003. The LIDAR data was acquired from a helicopter using an ALTM 3033 OPTECH instrument flying along strips at a height of $1000 \mathrm{~m}$ above ground level. The flying speed was 80 knots, scan angle 20 degrees and scan rate $33 \mathrm{KHz}$. The mean point density was specified to be greater than 1 point per $\mathrm{m}^{2}$ with first and last returns recorded. LIDAR returns were filtered into returns from vegetation, and bare ground resulting in an irregular density of ground returns that after filtering had an average point density of 0.26 points per $\mathrm{m}^{2}\left(3.8 \mathrm{~m}^{2}\right.$ per point). Figure 4 illustrates the distribution of bare ground LIDAR elevation points which contains occasional coverage gaps, 5-7 $\mathrm{m}$ in extent, in regions of dense vegetation. In our study the areas with the most regular density of ground returns are the grassland and landslide scar areas where only some shrubs are present.

\section{Methods}

Figure 5 illustrates the steps taken in processing the data to map terrain stability index, and most likely landslide initiation points. The numbers in the description that follow correspond to elements on the flowchart. The bare ground LIDAR data (1) consists of a set of elevation data points (2). These

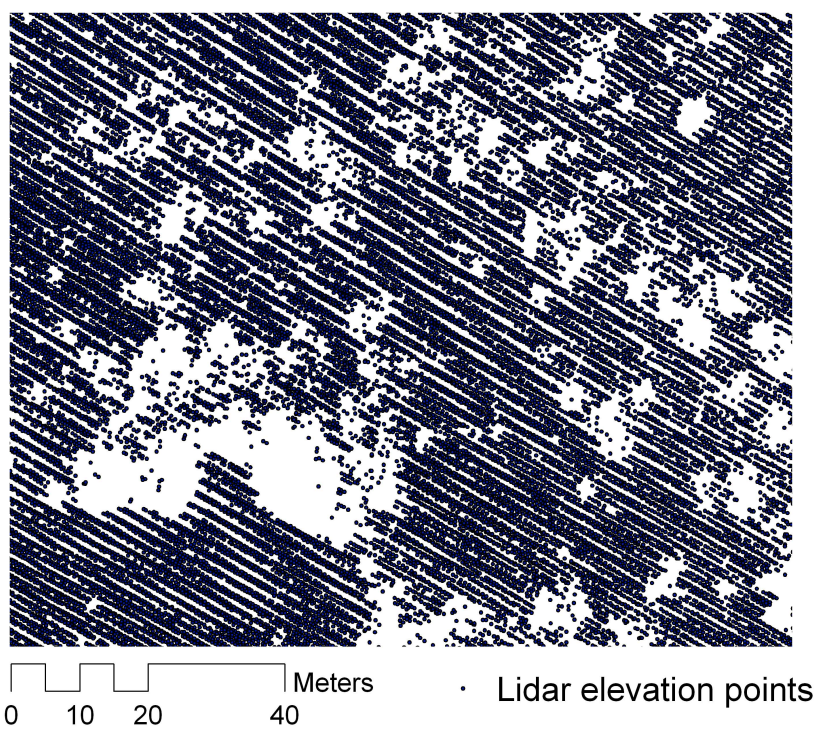

Fig. 4. Illustration of the irregular distribution of filtered LIDAR bare ground elevation points.

are used as input to the ArcGIS TOPOGRID (3) function to interpolate a digital terrain model (4) with specified grid cell size. The interpolation of digital terrain models from point data can result in artificial pits. Pits are regions of the digital terrain model surrounded by higher elevations that do not drain anywhere. The TOPOGRID algorithm is a spline technique that uses slope rather than curvature as the spline penalty function. This approach has been shown (Hutchinson, 1988; Hutchinson, 1989) to limit the occurrence of pits and produce digital terrain models that are hydrologically correct in the sense that there are fewer pits which result in internal drainage and incomplete contributing area values. The digital terrain model grids are used as input to the TauDEM $D \infty$ function (5) that calculates the terrain flow direction (6) and slope (7) grids. The TauDEM Area $D \infty$ function (8) is then used to calculate the specific catchment area (9). Specific catchment area and slope are the terrain inputs to SINMAP (11). SINMAP also takes as input geotechnical and hydrologic parameters (10) characterizing the physical properties of the study area. SINMAP produces a map of the terrain stability index, $S I$ (12). The stability index map together with flow direction grid serve as the inputs to the Path Minimum function (13) that evaluates the minimum stability index value upslope of (14) and downslope from (15) each grid cell. The minimum upslope and downslope grids, in combination with the stability index grid are used to determine the most likely landslide initiation point grid (16). Details of SINMAP and the algorithm for evaluation of most likely landslide initiation point are given below. This procedure was presented for most likely landslide initiation points determined from SINMAP. If slope, or another index of terrain stability is to be used the SINMAP output (12) needs to 


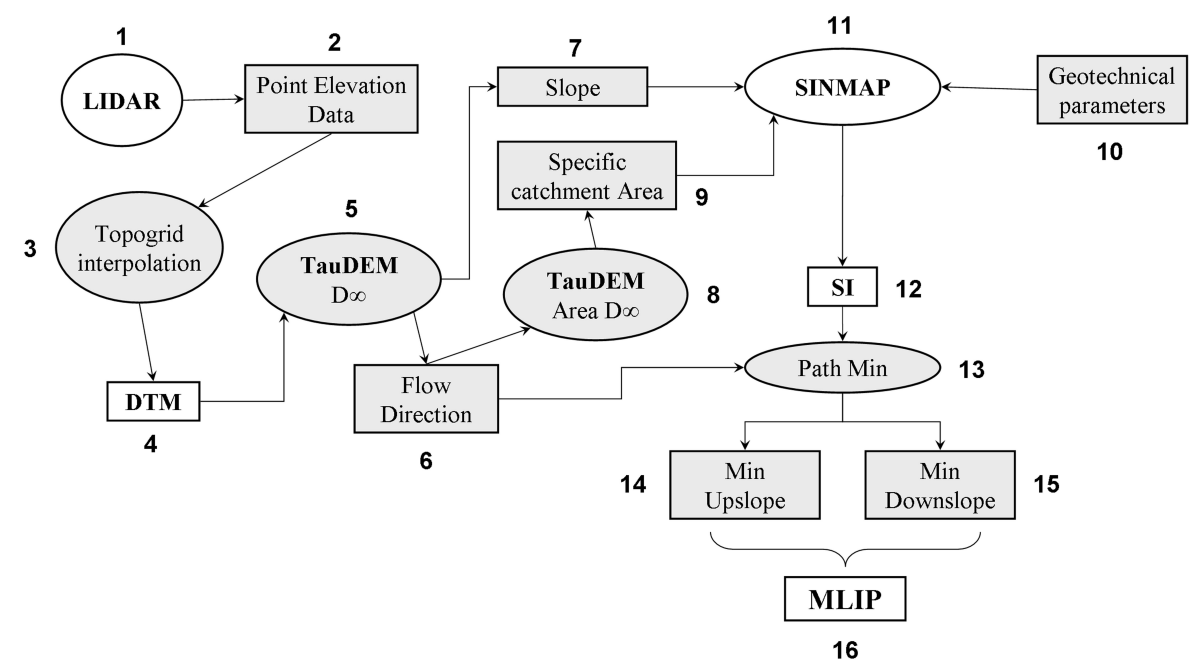

Fig. 5. Most likely landslide initiation model flow diagram.

be replaced by the other index. For SINMAP the critical stability index is the minimum $S I$ value, but for other indices, such as slope, the critical stability index may be the maximum value. In these cases the path maximum is evaluated using the maximum upslope and maximum downslope at elements (13) to (15) to determine the most likely initiation points for an index where maximum is critical.

Once stability index and most likely landslide initiation points have been derived they were evaluated by comparison to the observed landslide areas using density ratios. Five digital terrain models were interpolated for the study area with progressively finer grid cell resolutions of 50, 20, 10, 5 and $2 \mathrm{~m}$. For each of these digital terrain models slope and stability index SI from SINMAP were used as measures of terrain instability. Slope provides a simple empirical measure of terrain instability. Most likely landslide initiation points were then mapped for each digital terrain model grid and a range of stability index threshold values. For each stability index map corresponding to each digital terrain model grid resolution and a range of stability index thresholds we counted the number of grid cells within and outside the mapped landslide area with stability index less than the threshold value. This was used to determine the stability index density ratio using the following equation

density ratio of $S I=\frac{\left(S I_{\mathrm{lds}} / \text { landslide area }\right)}{\left(S I_{\mathrm{bas}} / \text { basin area }\right)}$

where $S I_{1 \mathrm{ds}}$ is the number of stability index cells less than the threshold that fall within the landslide area and $S I_{\text {bas }}$ is the total number of grid cells with stability index less than the threshold within the basin. For the most likely landslide initiation point map corresponding to each digital terrain model resolution and stability index threshold we counted the number of grid cells within and outside the mapped landslide area. This was used to determine the most likely landslide initiation point density ratio using the following equation

density ratio of $\mathrm{MLIP}=\frac{\left(P_{\mathrm{lds}} / \text { landslide area }\right)}{\left(P_{\mathrm{bas}} / \text { basin area }\right)}$

where $P_{\text {lds }}$ and $P_{\text {bas }}$ are respectively the number of most likely landslide initiation point grid cells within the landslide area and within the basin as a whole. The density ratios calculated using this procedure were used to compare stability index and most likely landslide initiation point maps developed using different digital terrain model resolutions and stability index threshold, $S_{\text {thr }}$. High values of the density ratio correspond to better performance of the model in discriminating areas where landslides have been observed.

\subsection{Stability index}

SINMAP (Pack et al., 1998) is based upon the infinite slope stability model (e.g. Hammond et al., 1992; Montgomery and Dietrich, 1994) that balances the destabilizing components of gravity and the restoring components of friction and cohesion on a failure plane parallel to the ground surface with edge effects neglected (Fig. 6). The infinite slope stability model factor of safety (ratio of stabilizing to destabilizing forces) used in SINMAP is given by the following equation

$F S=\frac{C+\cos \theta\left[1-\min \left(\frac{R}{T} \frac{a}{\sin \theta}, 1\right) r\right] \tan \phi}{\sin \theta}$

where $C$ is dimensionless cohesion, $r$ is the ratio of the density of water to the density of soil $\left(\rho_{w} / \rho_{s}\right), \theta$ is slope angle, $\phi$ the internal friction angle and $\min \left(\frac{R}{T} \frac{a}{\sin \theta}, 1\right)$ is an estimate of the relative wetness derived following TOPMODEL assumptions (Beven and Kirkby, 1979) of steady state drainage driven by a topographic gradient. Dimensionless cohesion, $C$, is defined as $\left(C_{r}+C_{s}\right) /\left(h \rho_{s} g\right)$, where $C_{r}$ and $C_{s}$ are root 
strength and soil cohesion terms, $h$ is the thickness of the soil (Fig. 6) and $g$ the gravitational constant. In the expression for relative wetness, $a(\mathrm{~m})$ is the specific catchment area derived from the DTM (Tarboton, 1997), $T$ is soil transmissivity $\left(\mathrm{m}^{2} / \mathrm{hr}\right) . R(\mathrm{~m} / \mathrm{hr})$ is a proportionality factor that relates relative wetness to the specific catchment area which can be interpreted as recharge under steady state assumptions.

In Eq. (3) $a$ and $\theta$ are derived from the DTM. SINMAP takes the geophysical parameters $C, R / T$ and $\tan \phi$ as uncertain and assumes that each has a uniform probability distribution. The stability index $(S I)$ is defined with respect to these probability distributions as the probability that a location is stable, i.e. has $F S>1$ (Pack et al., 1998).

$S I=\operatorname{prob}(F S>1)$

In the special case that $F S$ is greater than 1 for all values of $C, R / T$ and $\tan \phi$ within their uniform distribution ranges $S I$ is reported as the $F S$ value for the most conservative parameter values, namely the minimum $C$ and $\tan \phi$ and maximum $R / T$.

With the physical parameters being taken as uncertain, the parameters input to SINMAP become the minimum and maximum values of the ranges that define the uniform probability distributions. In SINMAP $T / R$ is used as an input parameter rather than $R / T$ because it has a physical interpretation as the hillslope length required for saturation under parallel flow conditions.

\subsection{Calculation of most likely landslide initiation points}

The numerical evaluation of most likely landslide initiation points is achieved in three steps. Inputs are a grid of stability index values and a grid of flow directions determined from the digital elevation model. First, based on the flow directions, the minimum stability index value downslope of each grid cell is computed and saved as the minimum downslope grid. Then, also based on the flow directions, the minimum stability index upslope from each grid cell is computed and saved as the minimum upslope grid. Most likely landslide initiation points are then identified as those points where the minimum downslope, minimum upslope and original stability index grid values are all equal. This procedure was followed so as to take advantage of the efficiency provided by a recursive evaluation of minimum downslope and minimum upslope values adapted from the recursive evaluation of contributing area used by Tarboton (1997) with the $D \infty$ multiple flow direction model for representation of flow over a terrain surface.

Figure 7 illustrates the minimum upslope and minimum downslope functions. Figure 7a is an example of a stability index grid. Figure $7 \mathrm{~b}$ gives a flow path through this grid. The values of the minimum upslope function along this flow path are given in Fig. 7c. Numerically the minimum upslope value is computed recursively as the minimum of the cell value itself and the result from the minimum upslope

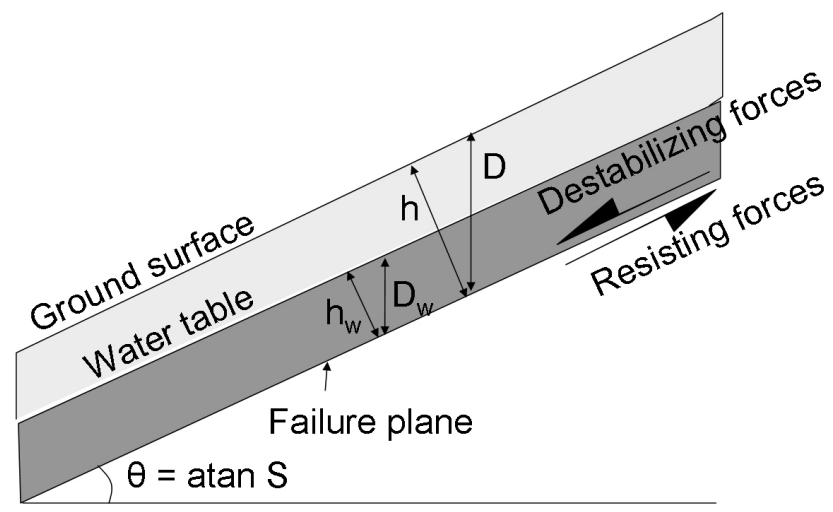

Fig. 6. Infinite slope stability model schematic.

function applied at grid cells immediately upslope. On the illustrated path the top left grid cell has no grid cells upslope so when the procedure is called the minimum upslope value is set equal to the cell value itself (in this case 0.8). When the procedure is called at the next grid cell down the minimum upslope value is the minimum of the cell immediately upslope (0.8) and the grid cell itself (0.7) resulting in a minimum upslope value of 0.7 in this case. Similarly at the third cell the minimum is 0.1 . At the fourth cell the evaluation is the minimum of the cell value of 0.5 and the minimum upslope of the third grid cell, 0.1 , resulting in a minimum upslope value of 0.1 for the fourth grid cell, and similarly for the fifth grid cell. In general there may be multiple grid cells immediately upslope of any specific grid cell, because flow paths merge. The $D \infty$ approach proportions flow between downslope grid cells. Grid cells that contribute $20 \%$ or more of their flow to a grid cell were counted as being upslope of a grid cell for the purposes of evaluating the minimum upslope grid value. The procedure was implemented in a $\mathrm{C}++$ computer program. Figure 7d illustrates the minimum downslope function, the computation of which is similar to the minimum upslope function except that instead of looking at each grid cell upslope from a specific grid cell it looks at each grid cell downslope from a specific grid cell.

The minimum upslope and minimum downslope grids are evaluated separately because recursion can not function in the upslope and downslope directions simultaneously. However once the minimum upslope and downslope grids have been evaluated the minimum value along a flow path can be identified by the condition that the minimum upslope value is equal to the minimum downslope value and the value at the grid cell itself. This is illustrated in Fig. 8. The most likely landslide initiation point method can be used without any condition on the values of stability index at the most likely landslide initiation locations. However, some flow paths that never go through an unstable location will still be identified as most likely landslide initiation points because they have the lowest stability index value along the flow path, but the 


\begin{tabular}{|l|l|l|l|l|}
\hline 0.8 & 0.5 & 0.7 & 0.4 & 0.8 \\
\hline 0.7 & 0.7 & 0.3 & 0.3 & 0.1 \\
\hline 0.9 & 0.8 & 0.1 & 0.2 & 0.4 \\
\hline 0.5 & 0.4 & 0.2 & 0.5 & 0.8 \\
\hline 0.3 & 0.4 & 0.7 & 0.8 & 0.9 \\
\hline
\end{tabular}

(a) Stability index

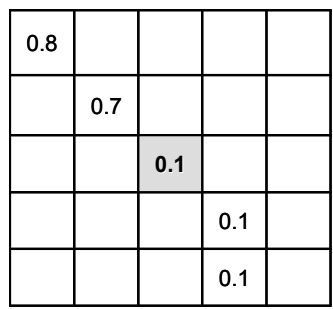

(c) Minimum upslope

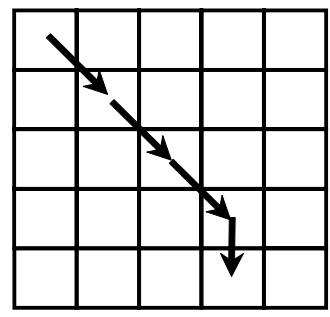

(b) Flow path

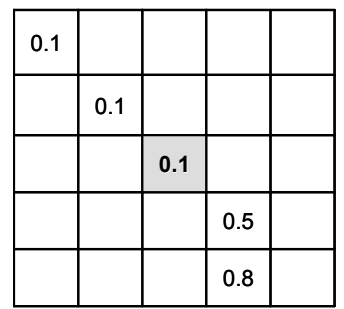

(d) Minimum downslope
Fig. 7. Illustration of the minimum upslope and downslope functions. (a) Example stability index grid. (b) Example flow path. (c) Example values of the minimum upslope function along the flow path in (b). (d) Example values of the minimum downslope function along the flow path in (b).

stability index value may be large and unlikely to be a landslide initiation point. Therefore we use a threshold with the identification of most likely landslide initiation points, only identifying most likely landslide initiation locations whose stability index value is less than the input threshold $S I_{t h r}$. In the illustration in Fig. 8, $S I_{\mathrm{thr}}=0.2$ results in identification of only the dark grid cells as most likely landslide initiation locations.

\section{Results}

For each of the five digital terrain models interpolated for the study area with progressively finer grid cell resolutions of 50,20, 10, 5 and $2 \mathrm{~m}$, slope and stability index, $S I$, from SINMAP were used as measures of terrain instability. Default SINMAP parameters were used so as to be objective without attempting calibration. These parameters were: 0 0.25 for the range of dimensionless cohesion, $C, 30^{\circ}-45^{\circ}$ for the range of internal frictional angle, $\phi$, and $2000-3000 \mathrm{~m}$ for the range of the ratio $T / R$. Slope thresholds of 1.05, 0.9, 0.52 and 0 , and SINMAP stability index thresholds of 0.2 , $0.5,1$ and 10 were specified and the number of grid cells in the domain meeting each threshold was tabulated (Table 1). The slope thresholds were chosen so that the percentage of area meeting each threshold are roughly equivalent to the percentages of area meeting the $S I$ thresholds so that later results are comparable. The percentages of area meeting each threshold can not be made the same for all grid cell resolutions while keeping the thresholds the same, so we chose to match the percentages for the highest resolution DTM grids. The slope threshold of 0 and SINMAP SI threshold of 10 are non-limiting thresholds that serve to select the entire domain.

Based on the stability index maps for each digital terrain model grid resolution, most likely landslide initiation locations were identified using the procedure described above. Slope thresholds of $0,0.52,0.9$, and 1.05 , and stability index thresholds, $S I_{\text {thr }}$ of $0.2,0.5,1$, and 10 were again used. Table 2 gives the number of most likely landslide initiation points identified for each DTM resolution and for each stability threshold. Table 2 also gives the percentage of the domain that these most likely landslide initiation points represent. Notice that these percentages are small because the most likely landslide initiation point procedure only identifies one point on each flow path. Notice also that these percentages are only weakly dependent on the stability criterion threshold, because in the majority of cases the most likely landslide initiation point selected meets all stability criteria.

The observed landslides were overlaid on the slope and $S I$ maps for each grid resolution and the percentage of the area exceeding the stability index criterion that occurs within the mapped landslide area was calculated. The results are given in Table 3 for slope and in Table 4 for SINMAP SI. Here exceeding the stability index criterion means slope greater than the threshold, or SINMAP SI less than the threshold. Based on the stability index maps for each digital terrain model grid resolution most likely landslide initiation locations were identified using the procedure described above, for slope thresholds of $0,0.52,0.9$, and 1.05 , and for stability index thresholds, $S I_{\text {thr }}$ of $0.2,0.5,1$, and 10 again. For each of these most likely landslide initiation point maps the percentage of most likely landslide initiation locations occurring within the mapped landslide area was calculated and also tabulated in Tables 3 and 4. Specifically for a grid resolution of $2 \mathrm{~m}$ there are 248379 grid cells with slope greater than or equal to 1.05 (Table 1). Of these 24753 occur within the mapped landslide area, representing a percentage of $10 \%$ as reported in Table 3. Similarly there are 245309 grid cells with $S I<0.2$ for a grid resolution of $2 \mathrm{~m}$ (Table 1). 27496 of these occur within the mapped landslide area representing a percentage of $11.2 \%$. For the MLIP percentages reported in Table 3 there are a total of 5828 MLIP grid cells identified using a slope threshold of 1.05 for a grid resolution of $2 \mathrm{~m}$ (Table 1). Of these 724 , representing $12.4 \%$ occur within the mapped landslide area.

The density ratio of stability index meeting each threshold criterion was calculated using Eq. (1) and presented in Table 5 for slope and Table 6 for SINMAP SI under the columns labeled slope and $S I$ respectively. The density ratio of most likely landslide initiation locations identified was calculated using Eq. (2) and presented in Table 5 for slope 
SI

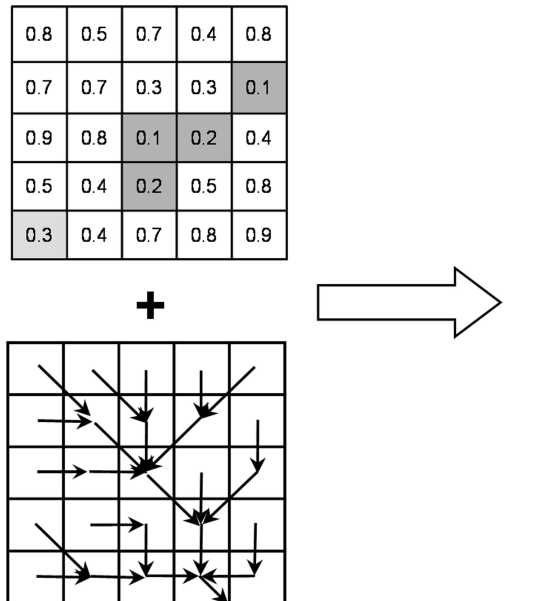

Flow Direction

\section{min SI downslope}

\begin{tabular}{|l|l|l|l|l|}
\hline 0.1 & 0.1 & 0.1 & 0.1 & 0.1 \\
\hline 0.1 & 0.1 & 0.1 & 0.1 & 0.1 \\
\hline 0.1 & 0.1 & 0.1 & 0.2 & 0.4 \\
\hline 0.4 & 0.2 & 0.2 & 0.5 & 0.8 \\
\hline 0.3 & 0.4 & 0.7 & 0.8 & 0.8 \\
\hline
\end{tabular}

\begin{tabular}{|l|l|l|l|l|}
\hline 0.8 & 0.5 & 0.7 & 0.4 & 0.8 \\
\hline 0.7 & 0.7 & 0.5 & 0.3 & 0.1 \\
\hline 0.9 & 0.8 & 0.1 & 0.2 & 0.1 \\
\hline 0.5 & 0.4 & 0.2 & 0.1 & 0.8 \\
\hline 0.3 & 0.3 & 0.2 & 0.1 & 0.8 \\
\hline
\end{tabular}
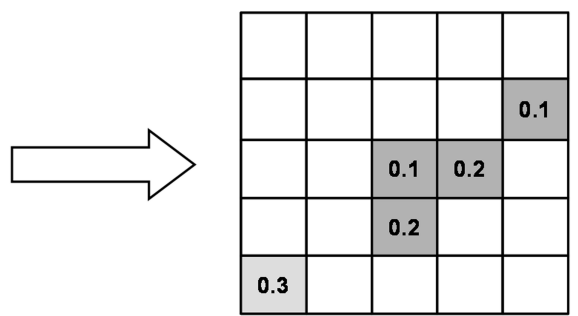

MLIP

\section{min SI upslope}

Fig. 8. Illustration of the combination of minimum upslope and minimum downslope functions to identify most likely landslide initiation points (MLIP). The shaded grid cells are identified as most likely landslide initiation points in all cases. The dark shaded grid cells are most likely landslide initiation points determined for $S I \leq S I_{\mathrm{thr}}=0.2$.

Table 1. Number of grid cells and percentage of the domain meeting each stability index threshold for each DTM grid resolution.

\begin{tabular}{lcccccccccc}
\hline Grid Resolution $(\mathrm{m})$ & \multicolumn{2}{c}{50} & \multicolumn{2}{c}{20} & \multicolumn{2}{c}{10} & & 5 & & 2 \\
\hline Thresholds & $\mathrm{n}$ & $\%$ & $\mathrm{n}$ & $\%$ & $\mathrm{n}$ & $\%$ & $\mathrm{n}$ & $\%$ & $\mathrm{n}$ & $\%$ \\
\hline Slope $\geq 1.05$ & 4 & 0.1 & 612 & 2.3 & 5402 & 5.1 & 31672 & 7.4 & 248379 & 9.3 \\
Slope $\geq 0.9$ & 178 & 4.2 & 2495 & 9.3 & 14908 & 14.0 & 72568 & 17.0 & 519394 & 19.4 \\
Slope $\geq 0.52$ & 2746 & 64.4 & 18542 & 69.4 & 75986 & 71.1 & 306918 & 71.8 & 1922810 & 72.0 \\
All Slopes & 4265 & 100.0 & 26712 & 100.0 & 106864 & 100.0 & 427407 & 100.0 & 2671290 & 100.0 \\
SI $<0.2$ & 92 & 2.2 & 1218 & 4.6 & 6731 & 6.3 & 33996 & 8.0 & 245309 & 9.2 \\
SI $<0.5$ & 447 & 10.5 & 3507 & 13.1 & 17065 & 16.0 & 75712 & 17.7 & 501811 & 18.8 \\
SI $<1$ & 3132 & 73.4 & 19920 & 74.6 & 79359 & 74.3 & 313497 & 73.3 & 1920411 & 71.9 \\
SI $<10$ & 4265 & 100.0 & 26712 & 100.0 & 106864 & 100.0 & 427407 & 100.0 & 2671288 & 100.0 \\
\hline
\end{tabular}

Table 2. Number of most likely landslide initiation point grid cells and percentage of the domain that these comprise derived from each stability index threshold for each DTM grid resolution.

\begin{tabular}{lcccccccccc}
\hline Grid Resolution $(\mathrm{m})$ & \multicolumn{2}{c}{50} & \multicolumn{2}{c}{20} & \multicolumn{2}{c}{10} & \multicolumn{3}{c}{5} & \\
\hline Thresholds & $\mathrm{n}$ & $\%$ & $\mathrm{n}$ & $\%$ & $\mathrm{n}$ & $\%$ & $\mathrm{n}$ & $\%$ & $\mathrm{n}$ & $\%$ \\
\hline Slope $\geq 1.05$ & 3 & 0.07 & 182 & 0.68 & 845 & 0.79 & 2439 & 0.57 & 5828 & 0.22 \\
Slope $\geq 0.9$ & 60 & 1.41 & 389 & 1.46 & 1245 & 1.17 & 3076 & 0.72 & 6315 & 0.24 \\
Slope $\geq 0.52$ & 260 & 6.10 & 742 & 2.78 & 1628 & 1.52 & 3516 & 0.82 & 6630 & 0.25 \\
All Slopes & 272 & 6.38 & 773 & 2.89 & 1733 & 1.62 & 3671 & 0.86 & 6887 & 0.26 \\
SI $<0.2$ & 20 & 0.47 & 206 & 0.77 & 1147 & 1.07 & 7186 & 1.68 & 65927 & 2.47 \\
SI $<0.5$ & 59 & 1.38 & 284 & 1.06 & 1332 & 1.25 & 7296 & 1.71 & 65967 & 2.47 \\
SI $<1$ & 150 & 3.52 & 472 & 1.77 & 1451 & 1.36 & 7340 & 1.72 & 65975 & 2.47 \\
SI $<10$ & 157 & 3.68 & 484 & 1.81 & 1461 & 1.37 & 7344 & 1.72 & 65994 & 2.47 \\
\hline
\end{tabular}


Table 3. Percentage of area with slope greater than threshold, and percentage of identified most likely landslide initiation points, MLIP, occurring within mapped landslide area.

\begin{tabular}{lcccccccccc}
\hline Grid Resolution $(\mathrm{m})$ & \multicolumn{2}{c}{50} & \multicolumn{2}{c}{20} & \multicolumn{2}{c}{10} & \multicolumn{2}{c}{5} & \multicolumn{2}{c}{2} \\
\hline Slope Thresholds & Slope & MLIP & Slope & MLIP & Slope & MLIP & Slope & MLIP & Slope & MLIP \\
\hline Slope $\geq 1.05$ & 0.0 & 0.0 & 7.8 & 3.8 & 9.4 & 9.2 & 9.5 & 11.8 & 10.0 & 12.4 \\
Slope $\geq 0.9$ & 6.7 & 6.7 & 6.9 & 5.7 & 8.9 & 10.8 & 9.5 & 11.0 & 9.3 & 11.6 \\
Slope $\geq 0.52$ & 6.5 & 4.2 & 6.2 & 6.2 & 6.2 & 10.0 & 6.2 & 10.0 & 6.2 & 11.1 \\
All Slopes & 4.7 & 4.0 & 4.7 & 6.0 & 4.7 & 9.3 & 4.7 & 9.6 & 4.7 & 10.7 \\
\hline
\end{tabular}

Table 4. Percentage of area with stability index, SI, less than threshold, and percentage of identified most likely landslide initiation points, MLIP, occurring within mapped landslide area.

\begin{tabular}{lcccccccccc}
\hline Grid Resolution $(\mathrm{m})$ & \multicolumn{2}{c}{50} & \multicolumn{2}{c}{20} & \multicolumn{2}{c}{10} & \multicolumn{2}{c}{5} & \multicolumn{2}{c}{2} \\
\hline SI thresholds & $S I$ & MLIP & SI & MLIP & SI & MLIP & SI & MLIP & SI & MLIP \\
\hline$S I<0.2$ & 16.3 & 25.0 & 11.8 & 8.7 & 12.5 & 18.2 & 11.2 & 14.2 & 11.2 & 12.28 \\
$S I<0.5$ & 10.7 & 15.3 & 10.9 & 9.2 & 10.7 & 17.5 & 10.7 & 14.0 & 10.4 & 12.27 \\
$S I<1$ & 6.4 & 7.3 & 6.1 & 6.8 & 6.2 & 16.9 & 6.2 & 13.9 & 6.3 & 12.27 \\
$S I<10$ & 4.7 & 7.0 & 4.7 & 6.6 & 4.7 & 16.8 & 4.7 & 13.9 & 4.7 & 12.26 \\
\hline
\end{tabular}

and Table 6 for SINMAP SI under the columns labeled MLIP.

\section{Discussion}

\subsection{Effectiveness of stability index}

The results presented above allow us to assess the effectiveness of the slope and the stability index map, and most likely landslide initiation procedure at discriminating potential landslide initiation locations in comparison to mapped landslide locations. Columns labeled slope in Table 3 represent the percentage of terrain within landslide scars that is greater than the indicated threshold. As the slope threshold is increased, moving up the column the percentage of terrain less than the slope threshold that falls within the mapped landslide scars generally increases (except for the small sample $50 \mathrm{~m}$ resolution case), reflecting the fact that a higher fraction of terrain with high values of slope falls within the mapped landslide scar. This increase is a measure of the effectiveness of the slope approach at discriminating terrain where landslide scars have been mapped. Columns labeled SI in Table 4 represent the percentage of terrain within landslide scars that is less than the indicated threshold. Specifically for the $50 \mathrm{~m}$ grid resolution all the terrain has $S I<10$ and $4.7 \%$ of the terrain is within mapped landslide scars so the percentage is 4.7. As the stability index threshold is reduced, moving up the column the percentage of terrain less than the stability index threshold that falls within the mapped land- slide scars increases, reflecting the fact that a higher fraction of terrain with low stability index falls within the mapped landslide scar. This increase is a measure of the effectiveness of the stability index approach at discriminating terrain where landslide scars have been mapped. The trend is essentially the same for all grid resolutions.

6.2 MLIP density ratios as a measure of stability index effectiveness

In Tables 5 and 6 the density ratio values provide a relative measure of the effectiveness of the stability index map to discriminate unstable terrain in comparison to the mapped landslide scars. We see that generally comparing Table 6 to Table 5 that the density ratios for $S I$ are greater than for slope providing a measure of the added value of contributing area in the SINMAP calculation at discriminating unstable terrain. This can also be seen comparing Tables 3 and 4 where area percentages are generally higher in Table 4. One can also observe in these tables that for DTM resolutions of $10 \mathrm{~m}$ and finer the percentages (in Tables 3 and 4) and density ratios (in Tables 5 and 6) are generally higher for most likely landslide initiation points than for SI. Specifically the SI density ratios in Table 6 indicate that at the lowest stability index threshold the ratio of density between points within and outside landslide scars is around 2.5, a measure of the effectiveness of simple stability index thresholding at discriminating landslide scars locations. However, as mentioned before, this comparison is hampered by the fact that mapped landslides included the entire landslide scar, not only the ini- 
Table 5. Density ratio between locations with stability index, slope, less than a threshold, and between most likely landslide initiation points, MLIP, within and outside the observed landslide area.

\begin{tabular}{lcccccccccc}
\hline Grid Resolution $(\mathrm{m})$ & \multicolumn{2}{c}{50} & \multicolumn{2}{c}{20} & \multicolumn{2}{c}{10} & \multicolumn{2}{c}{5} & \multicolumn{2}{c}{2} \\
\hline Slope Thresholds & Slope & MLIP & Slope & MLIP & Slope & MLIP & Slope & MLIP & Slope & MLIP \\
\hline Slope $\geq 1.05$ & 0 & 0 & 1.64 & 0.80 & 1.97 & 1.93 & 1.99 & 2.48 & 2.08 & 2.60 \\
Slope $\geq 0.9$ & 1.41 & 1.39 & 1.43 & 1.18 & 1.86 & 2.25 & 1.98 & 2.30 & 1.95 & 2.43 \\
Slope $\geq 0.52$ & 1.36 & 0.88 & 1.30 & 1.30 & 1.31 & 2.08 & 1.30 & 2.10 & 1.30 & 2.32 \\
All slopes & 1 & 0.85 & 1 & 1.24 & 1 & 1.95 & 1 & 2.01 & 1 & 2.24 \\
\hline
\end{tabular}

Table 6. Density ratio between locations with stability index, SI, less than a threshold, and between most likely landslide initiation points, MLIP, within and outside the observed landslide area.

\begin{tabular}{lcccccccccc}
\hline Grid Resolution $(\mathrm{m})$ & \multicolumn{2}{c}{50} & \multicolumn{2}{c}{20} & \multicolumn{2}{c}{10} & \multicolumn{2}{c}{5} & \multicolumn{2}{c}{2} \\
\hline$S I$ thresholds & $S I$ & MLIP & SI & MLIP & SI & MLIP & SI & MLIP & SI & MLIP \\
\hline$S I<0.2$ & 3.41 & 5.23 & 2.52 & 1.86 & 2.68 & 3.90 & 2.41 & 3.06 & 2.41 & 2.63 \\
$S I<0.5$ & 2.25 & 3.19 & 2.32 & 1.95 & 2.29 & 3.75 & 2.30 & 3.01 & 2.23 & 2.63 \\
$S I<1$ & 1.33 & 1.53 & 1.30 & 1.45 & 1.32 & 3.62 & 1.33 & 2.99 & 1.34 & 2.63 \\
$S I<10$ & 1 & 1.46 & 1.00 & 1.41 & 1.00 & 3.59 & 1.00 & 2.99 & 1.00 & 2.63 \\
\hline
\end{tabular}

tiation zones. The most likely landslide initiation point results allow us to assess the effectiveness of the most likely landslide initiation locations identified from the slope and stability index maps. The fact that MLIP density ratios are generally higher, with values as high as 3.9, suggests that in this setting, where mapped landslides include the entire landslide scar, the most likely landslide initiation point procedure is more effective at quantifying the effectiveness of the stability index map at discriminating potential landslide initiation locations.

We also note in Tables 5 and 6 that MLIP density ratios are less sensitive to threshold than slope or stability index. This is because MLIP is designed as a threshold independent approach with threshold functioning as a secondary screening. The lack of sensitivity to threshold suggests that MLIP does not suffer from some of the sensitivity issues that Begueria (2006) discusses and is a good measure for quantifying the effectiveness of the stability index map in terms of the difference in density of MLIP locations inside and outside of mapped landslides.

\subsection{Scale effects}

It is also of interest to note that the highest most likely landslide initiation point percentage and density ratios occur for a digital terrain model grid cell resolution of $10 \mathrm{~m}$, with the one exception of the smallest threshold and largest digital terrain model cell size. This is a small sample size effect that we disregard. With a $50 \mathrm{~m}$ cell size and 0.2 threshold there are only 20 most likely landslide initiation point grid cells, insuf- ficient to be representative. The peak in most likely landslide initiation point density ratios for digital terrain model grid cell resolution of $10 \mathrm{~m}$ we take as support for the idea that a $10 \mathrm{~m}$ digital terrain model grid cell resolution is optimal for the identification of potential instability in terrain stability mapping in this setting.

This $10 \mathrm{~m}$ scale may be a natural scale associated with the landslides under consideration. At scales coarser than $10 \mathrm{~m}$ the loss of information appears to result in a drop off in the discriminating capability of the stability index map as quantified by most likely landslide initiation point density ratio. At scales finer than $10 \mathrm{~m}$ small scale errors in the determination of slope, for example, may result in increases in the number of spurious most likely landslide initiation locations reducing the discriminating capability. Both the physical scale associated with the convergence of subsurface flow and the physical scale of a failure plane in the infinite slope model appear to have scale limits that contribute to a $10 \mathrm{~m}$ resolution digital terrain model having optimal discriminating capability in this study.

Figure 9 gives the most likely landslide initiation point map for part of the study area with $S I_{\mathrm{thr}}=1$, compared to mapped landslide scars. Note in this figure how most likely landslide initiation locations cluster at the upslope end of landslide scars indicating their most likely initiation points. Figure 10 illustrates the mapped most likely landslide initiation locations draped on an aerial photograph of part of the study area. Figure 11 illustrates the stability index and corresponding most likely landslide initiation points for a representative set of the digital terrain model resolutions used for 


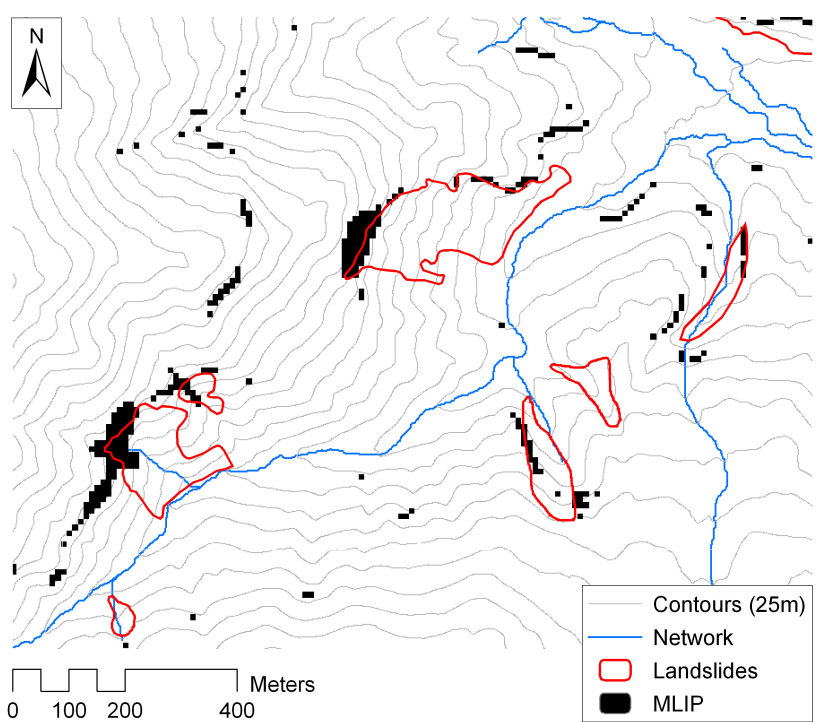

Fig. 9. Most likely landside initiation point map for $10 \mathrm{~m}$ resolution digital terrain model grid and $S I_{\mathrm{thr}}<1$.

one landslide complex. This figure shows the effects of DTM scale on terrain stability index and most likely landslide initiation points. At the $50 \mathrm{~m}$ resolution the digital terrain mode is too coarse to resolve the detail in the landslide scar. At $2 \mathrm{~m}$ resolution the most likely landslide initiation locations spread out as a blur, rather than a line of single most likely landslide initiation locations. The $10 \mathrm{~m}$ resolution DTM appears to offer a good resolution compromise for the identification of most likely landslide initiation points. At the $10 \mathrm{~m}$ scale there is some blurring of grid cells together but most of the identified locations are distinct and occur at or around the upper end of the mapped landslide scar.

In interpreting most likely landslide initiation point maps it is important to bear in mind that the procedure only identifies one most likely landslide initiation point along each flow path. The possibility exists that landslides may initiate at different locations along a unique flow line. Points may be identified as most likely landslide initiation points that have SI less critical than other cells because the other cells are not the most critical along a specific flow line. The threshold used in the procedure for identifying most likely landslide initiation points should be chosen to preclude identifying very stable non critical points. However one should keep in mind that most likely landslide initiation points do not quantify the potential terrain instability at each and every location. They are not a substitute for a stability index. Rather they are additional information that complements the information in a terrain stability map that were shown to be useful in this paper for evaluating the discriminating capability of a terrain stability map where comparison is against entire landslide scars, not only initiation regions. They may have other uses, for example as trigger points in dynamic

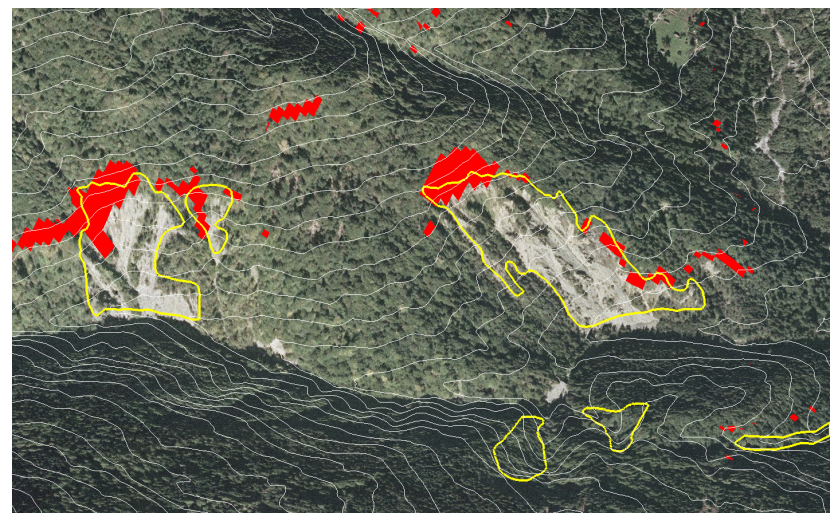

Fig. 10. 3-D view (same area as Fig. 9) of most likely landslide initiation locations ( $10 \mathrm{~m}$ digital terrain model resolution).

modelling or simulation of landslides, a potential use that we have not yet explored.

\section{Conclusions}

The most likely landslide initiation point (MLIP) method has been introduced as a new way to generate information from terrain stability maps. Most likely landslide initiation locations are of interest because they identify the most potentially unstable location along each flow path. They also provide a way to assess the discriminating capability of a terrain stability map in comparison to mapped landslide scars. This discriminating capability was measured using the ratio of the density of most likely landslide initiation locations within and outside mapped landslide scars. Most likely landslide initiation locations proved to have a greater discriminating capability than simple thresholding of the stability index map in the study area where this was applied where mapped landslide scars include runout areas. The most likely landslide inititiation point procedure may be used with any index of terrain stability. In this work we used both terrain slope and SINMAP stability index as indices of terrain stability. We made no effort to calibrate or adjust the SINMAP parameters; rather default model parameter were used. This was done to keep the evaluation of the most likely landslide initiation point approach general, without being dependent on specifically calibrated parameters. We found that ratios of the density of most likely landslide initiation points within and outside mapped landslide areas were significantly higher (3.6 to 3.9 for a $10 \mathrm{~m}$ resolution DTM) from SINMAP than from slope (1.9 to 2.2 for a $10 \mathrm{~m}$ resolution DTM). This allows us to conclude that the information provided by contributing area that is input to SINMAP results in terrain stability maps that are more discriminating than simply using slope as an index of terrain stability. We can also conclude that the most likely landslide initiation point procedure is effective at quantifying the discriminating capability of a terrain 
(a) $02550 \quad 100$ Meters
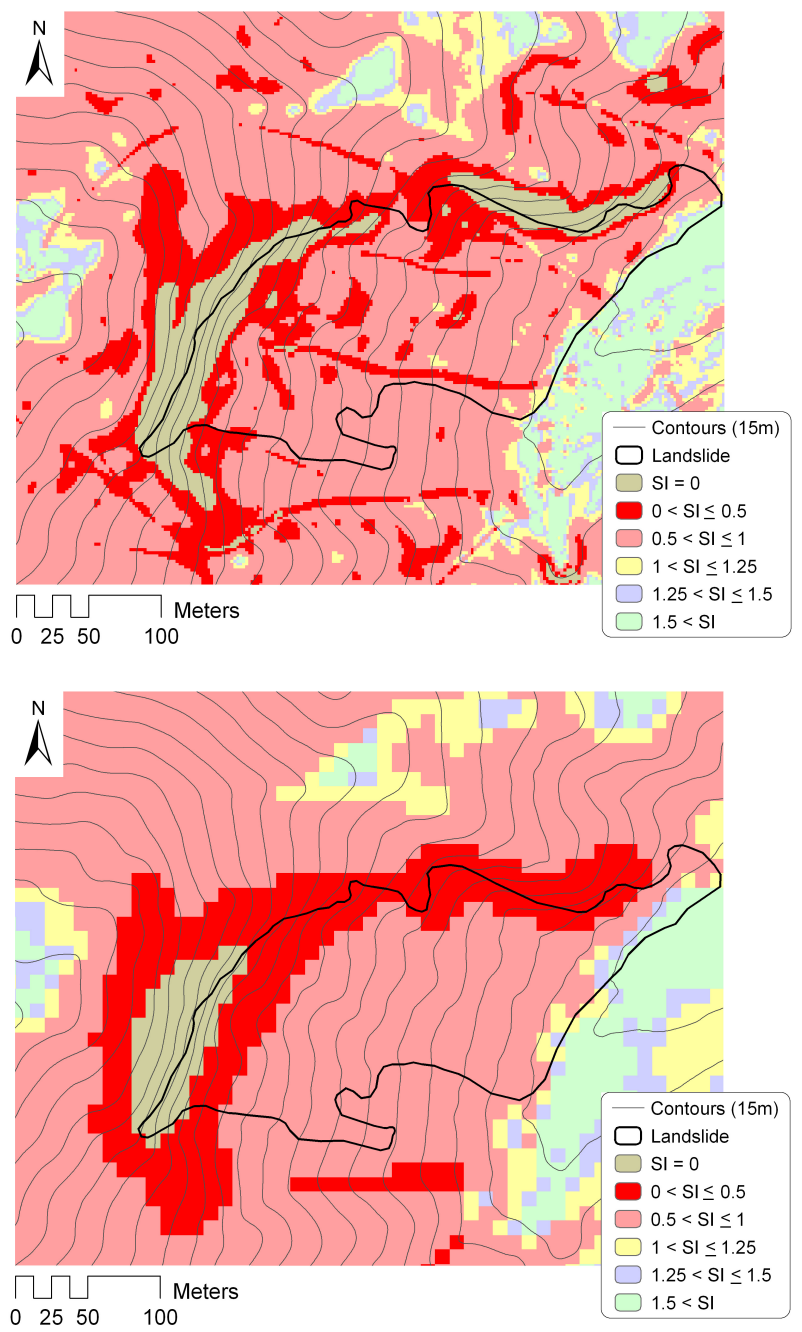

(c)

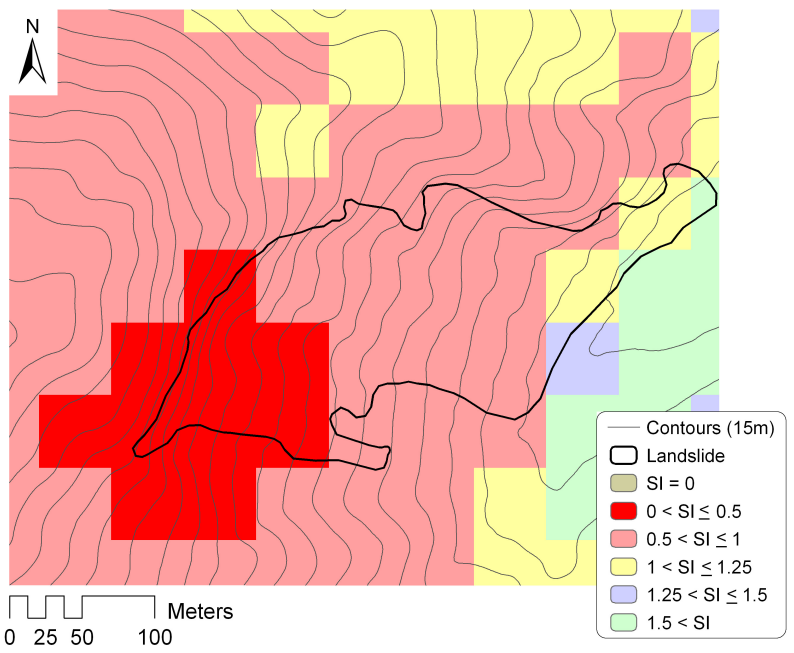

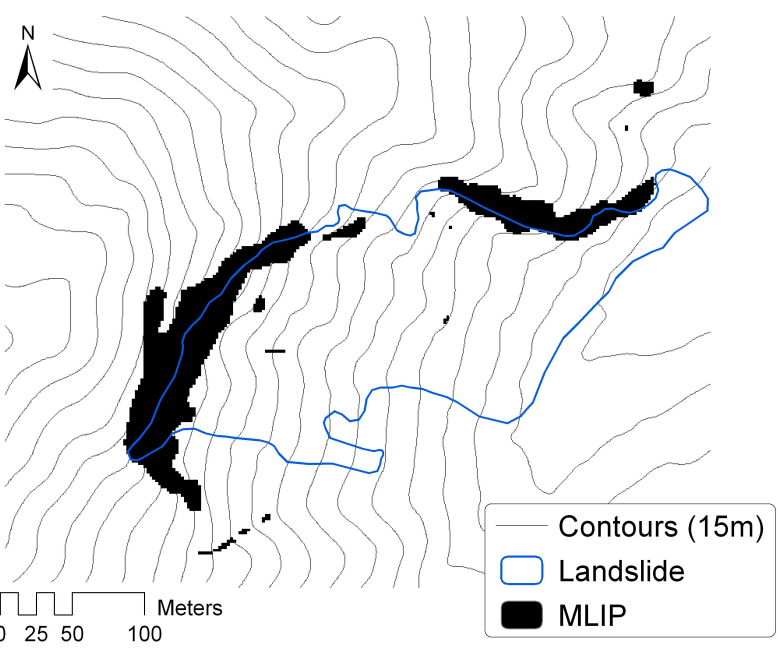

(b)

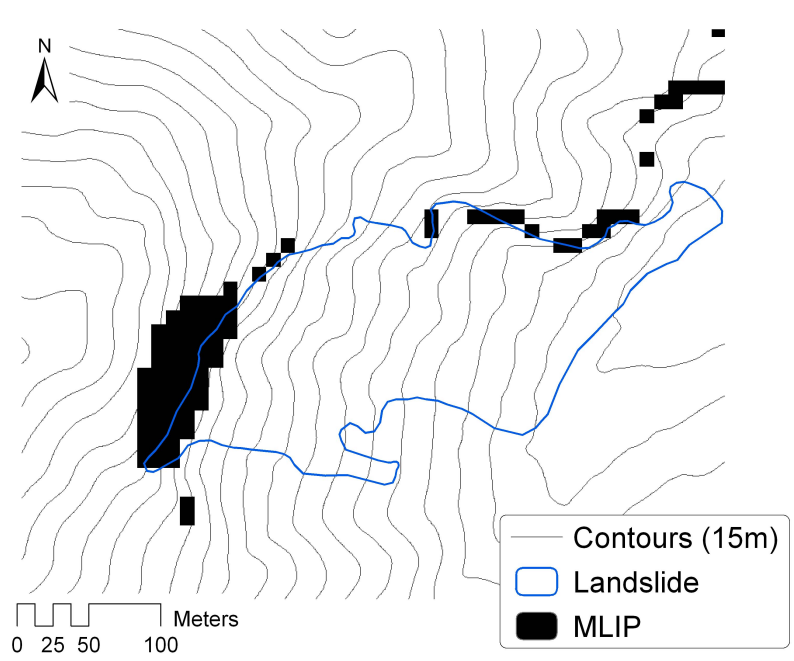

(d)

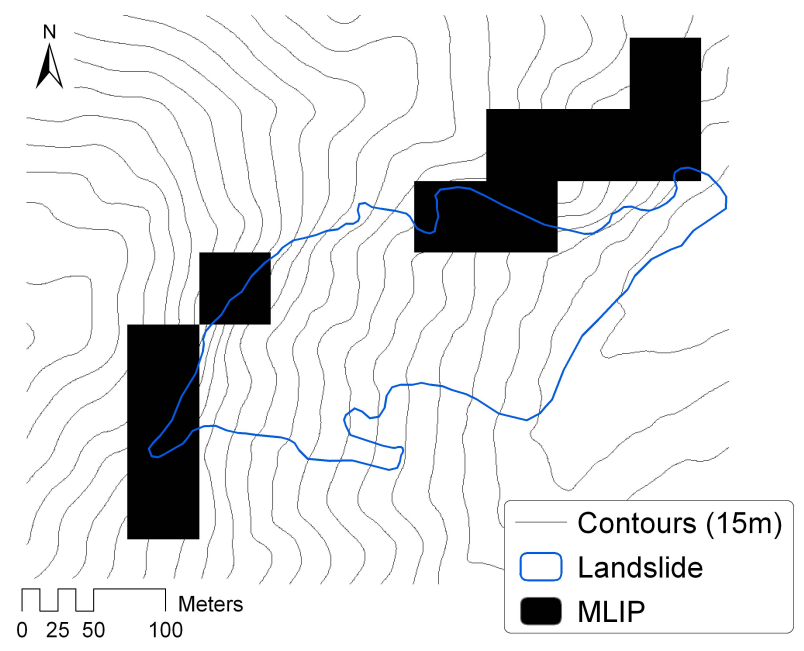

Fig. 11. Illustration of the stability index, and corresponding most likely landslide initiation locations identified for one landslide complex for representative digital terrain model resolutions used: (a) and (b) $2 \mathrm{~m}$ digital terrain model resolution, (c) and (d) $10 \mathrm{~m}$ digital terrain model resolution, (e) and (f) $50 \mathrm{~m}$ digital terrain model resolution. 
stability map in comparison to mapped landslide scars where the runout zone is included and useful for comparing different terrain stability models. Without calibration or input of site specific information, density ratios in excess of 3 of most likely landslide initiation point density between within landslide and outside of landslide area were obtained with the SINMAP terrain stability index. This suggests that SINMAP and the most likely landslide initiation point approach may have generality beyond our specific study area, a suggestion that merits further evaluation at other locations. The comparisons of most likely landslide initiation point density ratios for different resolution digital terrain models showed that for this data a $10 \mathrm{~m}$ resolution digital terrain model is optimal. Future work should test this approach in other settings and with other terrain stability models, such SHALSTAB (Montgomery and Dietrich, 1994) and Borga et al.'s (2002), quasi dynamic model.

Acknowledgements. This research was supported by the Interreg IIIB Spazioalpino project: CATCHRISK (Mitigation of hydrogeological risk in alpine catchments). The authors are grateful to "Servizio Territorio Montano e Manutenzioni” (Direzione Centrale Risorse Agricole, Naturali, Forestali e Montagna) of Friuli Venezia Giulia Region for the collaboration in field surveys and providing aerial photographs data. LIDAR data were collected in the Interreg IIIA Italia-Slovenia project: "Ricomposizione della cartografia catastale e integrazione della cartografia regionale numerica per i sistemi informativi territoriali degli enti locali mediante sperimentazione di nuove tecniche di rilevamento". This work has benefited from discussion with K. Chinnayakanahalli. Tarolli also acknowledges the contributions of G. Dalla Fontana and M. Borga during the prework discussion, and the support of Ing. Aldo Gini Foundation on the scholarship period at Utah State University.

Edited by: P. Molnar

\section{References}

Ackermann, F.: Airborne laser scanning - present status and future expectations, IS-PRN Journal of Photogrammetry and Remote Sensing, 54, 64-67, 1999.

Barling, R. D., Moore, I. D., and Grayson, R. B.: A Quasi-Dynamic Wetness Index for Characterizing the Spatial Distribution of Zones of Surface Saturation and Soil Water Content, Water Resour. Res., 30(4), 1029-1044, 1994.

Begueria, S.: Validation and evaluation of predictive models in hazard assessment and risk management, Natural Hazards, 37, 315329, 2006.

Beven, K. J., Lamb, R., Quinn, P. F., Romanowicz, R., and Freer, J.: TOPMODEL, in: Computer Models of Watershed Hydrology, edited by: Singh, V. P., Water Resour. Publ., 627-668, 1995.

Borga, M., Dalla Fontana, G., and Cazorzi, F.: Analysis of topographic and climatic control on rainfall-triggered shallow landsliding using a quasi-dynamic wetness index, J. Hydrol., 268(14), 56-71, 2002.

Borga, M., Dalla Fontana, G., Gregoretti, C., and Marchi, L.: Assessment of shallow landsliding by using a physically based model of hillslope stability, Hydrol. Processes, 16(14), 28332851, 2002.

Brenning, A.: Spatial Prediction Models for Landslide Hazards: Review, Comparison and Evaluation, Nat. Hazards Earth Syst. Sci., 5, 853-862, 2005, http://www.nat-hazards-earth-syst-sci.net/5/853/2005/.

Briese, C.: Breakline Modelling from Airborne Laser Scanner Data, PHD Thesis, Institute of Photogrammetry and Remote Sensing, Vienna University of Technology, 2004.

Chinnayakanahalli, K.: An Objective Method for the Intercomparison of Terrain Stability Models and Incorporation of Parameter Uncertainty, MS Thesis, Civil and Environmental Engineering, Utah State University, 2004.

Chung, C. J. and Fabbri, A. G.: Validation of spatial prediction models for landslide hazard mapping", Natural Hazards, 30, 451-472, 2003.

Chung, C. J. and Fabbri, A. G.: Systematic procedures of landslidehazard mapping for risk assessment using spatial prediction models, in: Landslide Hazard and Risk, edited by: Glade, T., Anderson, M. G., and Crozier, M. J., John Wiley \& Sons, Ltd., Chichester, England, 139-174, 2005.

Dietrich, W. E., Bellugi, D., and de Asua, R. R.: Validation of Shallow Landslide Model, Shalstab, for Forest Management, in: Land Use and Watersheds: Human Influence on Hydrology and Geomorphology in Urban and Forest Areas, edited by: Wigmosta, M. S. and Burges, S. J., Water Sci. Appl. 2, Amer. Geoph. Union, 195-227, 2001.

Dietrich, W. E., Wilson, C. J., Montgomery, D. R., McKean J., and Bauer, R.: Erosion Thresholds and Land Surface Morphology, Geology, 20, 675-679, 1992.

Freer, J., McDonnell, J. J. Beven, K. J., Peters, N. E., Burns, D. A., Hooper, R. P., Aulenbach, B., and Kendall, C.: The Role of Bedrock Topography on Subsurface Storm Flow, Water Resour. Res., 38(12), 1269, doi:10.1029/2001WR000872, 2002.

Hammond, C., Hall, D., Miller, S., and Swetik, P.: Level I Stability Analysis (LISA) Documentation for Version 2.0, General Technical Report INT-285, USDA Forest Service Intermountain Research Station, 1992.

Hutchinson, M. F.: Calculation of hydrologically sound digital elevation models, Third International Symposium on Spatial Data Handling, Sydney, Columbus, Ohio, International Geographical Union, 1988.

Hutchinson, M. F.: A new procedure for gridding elevation and stream line data with automatic removal of spurious pits, J. Hydrol., 106, 211-232, 1989.

Iverson, R. M.: Landslide Triggering by Rain Infiltration, Water Resour. Res., 36(7), 1897-1910, 2000.

Kraus, K. and Pfeifer, N.: Advanced DTM generation from LIDAR data, International Archives of Photogrammetry and Remote Sensing, XXXIV-3/W4, 23-35, 2001.

McKean, J. and Roering, J.: Objective landslide detection and surface morphology mapping using high-resolution airborne laser altimetry, Geomorphology, 57, 331-351, 2004.

Montgomery, D. R. and Dietrich, W. E.: A physically based model for the topographic control on shallow landsliding, Water Resour. Res., 30(4), 1153-1171, 1994.

Pack, R. T., Tarboton, D. G., and Goodwin, C. N.: The SINMAP Approach to Terrain Stability Mapping, 8th Congress of the International Association of Engineering Geology, Vancou- 
ver, British Columbia, Canada, 1998.

Tarboton, D. G.: A new method for the determination of flow directions and upslope areas in grid digital elevation models, Water Resour. Res., 33, 309-319, 1997.
Wu, W. and Sidle, R. C.: A Distributed Slope Stability Model for Steep Forested Watersheds, Water Resour. Res., 31(8), 20972110, 1995. 